\title{
Antioxidant HPTLC-DPPH Fingerprinting of Honeys and Tracking of Antioxidant Constituents upon Thermal Exposure
}

\author{
Md Khairul Islam ${ }^{1,2}$, Tomislav Sostaric ${ }^{2}$, Lee Yong Lim ${ }^{2}$, Katherine Hammer ${ }^{1,3}$ and Cornelia Locher ${ }^{1,2, *}$ \\ 1 Cooperative Research Centre for Honey Bee Products Limited (CRC HBP), University of Western Australia, \\ Myers Building, M087, Perth 6009, Australia; mdkhairul.islam@research.uwa.edu.au (M.K.I.); \\ katherine.hammer@uwa.edu.au (K.H.) \\ 2 Division of Pharmacy, School of Allied Health, University of Western Australia, Crawley 6009, Australia; \\ tom@chromatechscientific.com (T.S.); lee.lim@uwa.edu.au (L.Y.L.) \\ 3 School of Biomedical Sciences, University of Western Australia, Crawley 6009, Australia \\ * Correspondence: Connie.Locher@uwa.edu.au
}

Citation: Islam, M.K.; Sostaric, T.; Lim, L.Y.; Hammer, K.; Locher, C. Antioxidant HPTLC-DPPH Fingerprinting of Honeys and Tracking of Antioxidant Constituents upon Thermal Exposure. Foods 2021, 10, 357. https://doi.org/10.3390/ foods 10020357

Academic Editor: Miguel Palma Lovillo

Received: 10 January 2021

Accepted: 3 February 2021

Published: 7 February 2021

Publisher's Note: MDPI stays neutral with regard to jurisdictional claims in published maps and institutional affiliations.

Copyright: (c) 2021 by the authors. Licensee MDPI, Basel, Switzerland. This article is an open access article distributed under the terms and conditions of the Creative Commons Attribution (CC BY) license (https:// creativecommons.org/licenses/by/ $4.0 /)$.

\begin{abstract}
The use of High-Performance Thin-Layer Chromatography (HPTLC) coupled with the use of $\mathrm{DPPH}^{*}$ (2,2-diphenyl-1-picrylhydrazyl) as a derivatisation reagent is a novel approach to the analysis of antioxidant activity of honeys. The method facilitates the visualisation of individual constituents that contribute to the overall antioxidant activity of the honey, even if they are not yet chemically identified, and allows for the quantification of their antioxidant activity as gallic acid equivalents. The method supports a more in-depth study of the antioxidant activity of honey as it allows for a comparative analysis of the antioxidant fingerprints of honeys of different floral origin and is able to capture differences in their individual bioactive constituents. Further, it supports the tracking of changes in antioxidant activity of individual honey constituents over time upon exposure to different temperature conditions, which demonstrates the potential value of the method for in-process quality control.
\end{abstract}

Keywords: food analysis; antioxidant band activity; Leptospermum; Eucalyptus; Marri; degradation monitoring

\section{Introduction}

Honey, a highly concentrated complex mixture of mainly sugars (75-85\%), water (13-21\%), and a small fraction of non-sugar constituents (approx. 3\%) [1-3], has been appreciated for centuries-not only as a food item, but also for its medicinal properties [4]. The earliest recorded medicinal use of honey dates back to the Ancient Egyptian era [5,6]. To date, a range of bioactivities have been investigated, amongst them antimicrobial, antioxidant, anti-inflammatory, anticancer, antidiabetic, anti-hyperlipidemic, anti-ulcer, as well as radical scavenging and wound-healing activities [7-10]. Next to its antibacterial effects, the antioxidant activity of honey is of growing interest-although, to date, only a few studies have investigated the specific constituents that are responsible for this effect [11].

Free radicals cause oxidative stress on living tissues by damaging biomolecules essential for cell vitality, and are thus implicated in many conditions, like inflammation, cardiovascular diseases, cancer, and neuro-degenerative diseases [12,13]. Antioxidants have the ability to counteract these damaging effects. Phytochemicals, such as phenolic acids and flavonoids, are believed to be strongly correlated to the antioxidant properties of natural products promoted for human health benefits [14,15]. Phenolic acids and flavonoids represent a significant share of the non-sugar constituents of honey, and as such, not only contribute to its colour and organoleptic characteristics, but also to its bioactivity, including its antioxidant properties [16]. Commonly, the honey's colour is seen as an indication for activity - the darker the honey, the higher its total phenolics content, and by extension, 
also its antioxidant properties [17,18]. Depending on the honey's floral source, its phenolic acid and flavonoid profile can vary significantly. Thus, in particular for monofloral honeys, their phenolics profile is a distinguishing feature that will impact the honeys' organoleptic characteristics and bioactivity levels, and with this, ultimately also their quality and the price they can yield [19].

While in general, the presence of phenolic constituents has been correlated with a honey's antioxidant activity, detailed studies on the chemical nature of these phenolics and investigations on the potential contribution of non-phenolics to the overall antioxidant activity are sparse. Further, only limited comparative analyses between honeys have been carried out with respect to their antioxidant effects [11]. Depending on a honey's constituent profile, different levels of antioxidant activity can be anticipated. Further, it can also be assumed that honeys, which are comparable in their overall antioxidant activity, might not necessarily have identical bioactive constituent profiles. It is therefore beneficial to visualise and quantify the various antioxidant phytochemicals that are present in honeys, even if their chemical identity is not yet known, and to establish similarities and differences in the respective activity profiles of different monofloral honeys.

Maintaining the level of antioxidant constituents present in honeys throughout the production, transport, and storage chain is of concern to the beekeeping industry, as it will ensure the ongoing quality of its products. Antioxidant assays can support a better understanding of the way these processes might affect bioactivity. Among the various antioxidant assays that exist, the DPPH assay is one of the most popular spectrophotometric assays for the determination of the total antioxidant activity of honeys [20,21]. DPPH* (2,2-diphenyl-1-picrylhydrazyl) is a stable free radical, which is sensitive to reaction with Lewis bases. It is characterised by an intense purple colour (absorbance at 515-520 nm), which is lost upon reaction with oxidising reagents. In particular, constituents which can rapidly decrease the absorbance of $\mathrm{DPPH}^{*}$ by donating a hydrogen atom are considered good antioxidants. However, a significant advantage of the assay is that $\mathrm{DPPH}^{*}$ reacts even with weak antioxidants if sufficient reaction time is given [22,23].

High-Performance Thin-Layer Chromatography (HPTLC) is a simple but increasingly popular tool, used for the analysis of natural products like honey [24-26]. It allows for the separation, and potentially also the quantification of various extract constituents using a semi-automated set-up. In this study, the method is coupled with DPPH* derivatisation [27] and applied to a range of commercially available honeys from Western Australia (Table 1) to determine commonalities and differences in their individual antioxidant constituent profiles. Further, it is demonstrated how HPTLC-DPPH fingerprinting can be used to track honey constituents over time in order to determine the potential impact of processing stressors (e.g., elevated temperature) on the activity of the honey's antioxidant constituents. This is relevant as honeys are, for instance, routinely warmed (between $55-80{ }^{\circ} \mathrm{C}$ ) $[28,29]$ to facilitate filtration to remove debris from raw honey and dispense into packaging jars. Furthermore, particularly in warmer climates, honeys might also be exposed to elevated temperatures during their storage. It has been demonstrated that heat exposure can impact on honeys' antibacterial activity [30] and potentially also lead to the formation of unwanted by-products, such as hydroxymethylfurfural [31,32], but the effect on honeys' antioxidant activity has not yet been studied to the same extent. 
Table 1. Honey samples.

\begin{tabular}{cccc}
\hline $\begin{array}{c}\text { Labelled } \\
\text { Floral Source }\end{array}$ & Nectar Source & $\begin{array}{c}\text { Supplier and } \\
\text { Packaging Date }\end{array}$ & $\begin{array}{c}\text { Reference } \\
\text { ID }\end{array}$ \\
\hline Manuka & Leptospermum spp. & $\begin{array}{c}\text { Barnes Naturals } \\
\text { (January 2017) }\end{array}$ & LEP \\
\hline Coastal Peppermint & Agonis flexuosa & $\begin{array}{c}\text { Margaret River } \\
\text { Honey Co. } \\
\text { (December 2017) }\end{array}$ & AGO \\
\hline Marri & Corymbia calophylla & $\begin{array}{c}\text { ICON Honey } \\
\text { (February 2018) }\end{array}$ & COR \\
\hline Karri & Eucalyptus diversicolor & $\begin{array}{c}\text { Zees Bees } \\
\text { (2016) }\end{array}$ & EU1 \\
\hline River Red Gum & $\begin{array}{c}\text { Eucalyptus } \\
\text { camaldulensis }\end{array}$ & $\begin{array}{c}\text { Capilano } \\
\text { (May 2014) }\end{array}$ & EU2 \\
\hline Organic & Unknown & $\begin{array}{c}\text { Wescobee } \\
\text { (December 2016) }\end{array}$ & MF1 \\
\hline Multifloral & Unknown & $\begin{array}{c}\text { Wescobee } \\
\text { (June 2019) }\end{array}$ & MF2 \\
\hline Unspecified & Unknown & $\begin{array}{c}\text { Coles Supermarket } \\
\text { (Jan 2019) }\end{array}$ & UN1 \\
\hline Unspecified & Unknown & $\begin{array}{c}\text { Aldi Supermarket } \\
\text { (No date provided) }\end{array}$ & UN2 \\
\hline
\end{tabular}

\section{Materials and Methods}

\subsection{Chemicals and Reagents}

Reagents were sourced from: 4,5,7-trihydroxyflavanone (Alfa Aesar, Lancashire, UK), gallic acid (Ajax Chemicals Ltd., Sydney, Australia), DPPH* (Fluka AG, Buchs SG, Switzerland), and anhydrous sodium sulfate (Merck KGaA, Darmstadt, Germany). Solvents were purchased from: Methanol (Scharlau, Barcelona, Spain), dichloromethane (Merck KGaA, Darmstadt, Germany), toluene (APS Chemicals, Sydney, Australia), vanillin (SigmaAldrich, St. Louis, MO, USA), ethyl acetate, and formic acid (Ajax Finechem Pvt Ltd., Sydney, Australia). Commercial honeys (Table 1) were obtained from supermarkets and honey suppliers in Western Australia. Where possible, the honey's floral source was derived from the label, and no further authentication was carried out.

\subsection{Sample Preparation}

\subsubsection{Standard Solution and Reagent Preparations}

A standard stock solution of gallic acid $(20 \mu \mathrm{g} / \mathrm{mL})$ in methanol and a reference solution of $0.5 \mathrm{mg} / \mathrm{mL}$ of 4,5,7-trihydroxyflavanone in methanol were prepared. A mixture of toluene: ethyl acetate: formic acid $(6: 5: 1, v / v / v)$ was used as the mobile phase [33]. The derivatisation reagent was prepared by dissolving $40 \mathrm{mg} \mathrm{DPPH}^{*}$ in $10 \mathrm{~mL}$ of $50 \%$ methanol and 50\% ethanol and stored in an amber glass bottle, protected from light, until use [34]. A vanillin spraying reagent was prepared by adding $2 \mathrm{~mL}$ of sulfuric acid to $100 \mathrm{~mL}$ vanillin solution $(1 \mathrm{~g} / 100 \mathrm{~mL}$ in ethanol).

\subsubsection{Honey Sample Preparation}

For the analysis, $1 \mathrm{~g}$ of each commercial honey was mixed with $2 \mathrm{~mL}$ of deionised water in a glass stoppered tube, and then vortexed to produce a homogenous solution. The aqueous honey solutions were then extracted three times with $5 \mathrm{~mL}$ of dichloromethane. The combined organic extracts were dried with anhydrous $\mathrm{MgSO}_{4}$, filtered, and evaporated to dryness at room temperature. The dried extracts were stored at $4{ }^{\circ} \mathrm{C}$ until further analysis. Prior to HPTLC analysis, the samples were reconstituted in $100 \mu \mathrm{L}$ of dichloromethane. 


\subsection{Chromatography}

Two plates were prepared for the analysis, where one was used to visualise and quantify antioxidant honey constituents, and the other to obtain the honey's floral fingerprint [35].

\subsubsection{Sample Application}

For the quantification of antioxidant honey constituents as gallic acid equivalents, $4 \mu \mathrm{L}$ of the reference solution, $4 \mu \mathrm{L}$ of the gallic acid standard solution, and $5 \mu \mathrm{L}$ each of the respective honey extracts were applied as $8 \mathrm{~mm}$ bands at $8 \mathrm{~mm}$ from the lower edge of the HPTLC plate at a rate of $150 \mathrm{~nL} \mathrm{~s}^{-1}$ using a semi-automated HPTLC application device (Linomat 5, CAMAG). To prepare a gallic acid standard curve in the honey matrix, $2 \mu \mathrm{L}, 3 \mu \mathrm{L}, 4 \mu \mathrm{L}, 5 \mu \mathrm{L}, 6 \mu \mathrm{L}$, and $7 \mu \mathrm{L}$ of gallic acid standard solution were applied by over-spotting the respective honey bands. To obtain the honeys' floral fingerprint, only honey extracts ( $5 \mu \mathrm{L}$ each) were applied to the plate.

\subsubsection{Development}

For each plate, the chromatographic separation was performed on silica gel $60 \mathrm{~F}_{254}$ HPTLC plates (glass plates $20 \mathrm{~cm} \times 10 \mathrm{~cm}$, Merck, Darmstadt, Germany) in a saturated (33\% relative humidity), automated development chamber (ADC2, CAMAG). The plates were pre-saturated with the mobile phase for $5 \mathrm{~min}$, automatically developed to a distance of $70 \mathrm{~mm}$ at room temperature, and dried for $5 \mathrm{~min}$. The obtained chromatographic results were documented using a HPTLC imaging device (TLC Visualizer 2, CAMAG) under white light. The chromatographic images were digitally processed and analysed using specialised HPTLC software (visionCATS, CAMAG), which was also used to control the individual instrumentation modules $[25,33,35]$.

\subsubsection{Derivatisations}

After initial documentation of the chromatographic results, the first plate was derivatised with $3 \mathrm{~mL}$ of $0.4 \% \mathrm{DPPH}^{*}$ reagent (CAMAG Derivatizer). The derivatised plates were again analysed with the HPTLC imaging device under white light, and images were taken 60 min after derivatisation.

To obtain the floral fingerprints, the second plate was derivatised with $3 \mathrm{~mL}$ of vanillin spraying reagent (CAMAG Derivatizer). The derivatised plate was heated (CAMAG TLC Plate Heater III) at $100{ }^{\circ} \mathrm{C}$ for 3 min until colour developed before being analysed (TLC Visualizer, CAMAG) under white light and $366 \mathrm{~nm}$.

\subsubsection{Data Analysis and Statistics}

For the quantification of antioxidant honey constituents as gallic acid equivalents, the obtained images were converted into individual absorbance points according to their Rf values. Using Excel@ , the obtained data were converted into chromatograms, which were used to derive calibration curves of area of absorbance vs. concentration [27]. All experiments were performed in triplicates, and the results were evaluated by a one-way analysis of variance (ANOVA) followed by Tukey's honestly significant difference (TukeyHSD) test, where a $p$-value of less than 0.05 was considered statistically significant. All statistical analyses were performed using Microsoft Office 365, R and R studio [36].

\subsection{Validation}

The quantification of antioxidant activity of honey extracts using HPTLC in combination with $\mathrm{DPPH}^{*}$ derivatisation is fully validated, as described previously [27]. In brief, data were generated by plotting the peak area vs. applied amount of gallic acid standards in a range of 40-140 $\mathrm{ng} / \mathrm{band}$. Linearity of the assay was calculated based on the regression equation and correlation $\left(\mathrm{r}^{2}\right)$ coefficient. The sensitivity, expressed as the limit of detection (LOD) and limit of quantification (LOQ), was based on the comparison of the standard deviation (SD) and the slope of the calibration curve, and was found to be $16.5 \mathrm{ng}$ 
and $50 \mathrm{ng}$, respectively. The accuracy of mean recoveries was found to be in the range of 99.89-101.45\%. Precision as intra-day precision was determined by analysing replicates of three known concentrations in triplicate $(n=3)$ within a single day. Precision as inter-day precision was determined by repeating the same experiment on different days. Variance between replicates was expressed as relative standard deviation (\%RSD), and the obtained values (1.01-2.52\% RSD) were within the acceptance range.

\subsection{Thermal Exposure}

Honey samples were placed in glass jars and kept at a constant temperature of $40{ }^{\circ} \mathrm{C}$ and $60{ }^{\circ} \mathrm{C}$, respectively, using a temperature-controlled heating oven (Memmert $\mathrm{GmbH}$ + Co. KG, Büchenbach, Germany). Sampling was carried out at $0 \mathrm{~min}, 12 \mathrm{~h}, 24 \mathrm{~h}$, and $48 \mathrm{~h}$. The honey samples were extracted, their floral fingerprints and antioxidant profiles recorded, and their antioxidant band activities calculated according to the process described earlier.

\section{Results and Discussion}

\subsection{Antioxidant Band Activity of Honeys}

The chromatograms of the HPTLC images obtained for the various organic honey extracts after derivatisation with $\mathrm{DPPH}^{*}$ reagent is presented in Figure 1. The antioxidant activity of bands was quantified and expressed as mg gallic acid equivalents per $100 \mathrm{~g}$ of honey (Table 2).

Table 2. Antioxidant activity of individual bands in organic honey extracts.

\begin{tabular}{|c|c|c|c|c|c|}
\hline ID & Bands & $\mathbf{R f}$ & $\begin{array}{c}\text { Concentration } \\
\text { (ng/5 } \mu \mathrm{L} \\
\text { Extracts) }\end{array}$ & $\begin{array}{l}\text { mg Gallic Acid } \\
\text { Equivalent (per } \\
100 \text { g Honey) }\end{array}$ & $\begin{array}{c}\text { Total Band Activity } \\
\text { (mg Gallic Acid Equivalent } \\
\text { per } 100 \text { g Honey) }\end{array}$ \\
\hline \multirow{3}{*}{ LEP } & 1 & 0.27 & 80.32 & 0.1606 & \multirow{3}{*}{0.9685} \\
\hline & 2 & 0.47 & 356.08 & 0.7122 & \\
\hline & 3 & 0.83 & 47.85 & 0.0957 & \\
\hline \multirow{3}{*}{ AGO } & $1 *$ & 0.35 & 25204 & 07041 & \multirow{3}{*}{0.8101} \\
\hline & $2 *$ & 0.49 & 352.04 & 0.7041 & \\
\hline & 3 & 0.78 & 53.02 & 0.1060 & \\
\hline \multirow{3}{*}{ EU1 } & 1 & 0.30 & 31.06 & 0.0621 & \multirow{3}{*}{0.2244} \\
\hline & 2 & 0.46 & 34.46 & 0.0689 & \\
\hline & 3 & 0.80 & 46.67 & 0.0933 & \\
\hline \multirow{2}{*}{ COR } & 1 & 0.43 & 113.67 & 0.2273 & \multirow{2}{*}{0.3615} \\
\hline & 2 & 0.81 & 67.09 & 0.1342 & \\
\hline \multirow{3}{*}{ EU2 } & 1 & 0.08 & 47.42 & 0.0948 & \multirow{3}{*}{0.5041} \\
\hline & 2 & 0.41 & 129.55 & 0.2591 & \\
\hline & 3 & 0.80 & 75.06 & 0.1501 & \\
\hline \multirow{4}{*}{ MF1 } & 1 & 0.09 & 32.84 & 0.0657 & \multirow{4}{*}{0.3638} \\
\hline & 2 & 0.31 & 34.08 & 0.0682 & \\
\hline & 3 & 0.48 & 54.53 & 0.1091 & \\
\hline & 4 & 0.81 & 60.47 & 0.1209 & \\
\hline \multirow{2}{*}{ MF2 } & 1 & 0.46 & 64.50 & 0.1290 & \multirow{2}{*}{0.2527} \\
\hline & 2 & 0.81 & 61.83 & 0.1237 & \\
\hline \multirow{3}{*}{ UN1 } & 1 & 0.08 & 22.02 & 0.0440 & \multirow{3}{*}{0.1831} \\
\hline & 2 & 0.51 & 51.13 & 0.1022 & \\
\hline & 3 & 0.81 & 18.50 & 0.0369 & \\
\hline UN2 & \multicolumn{2}{|c|}{ Not detected } & & & \\
\hline
\end{tabular}




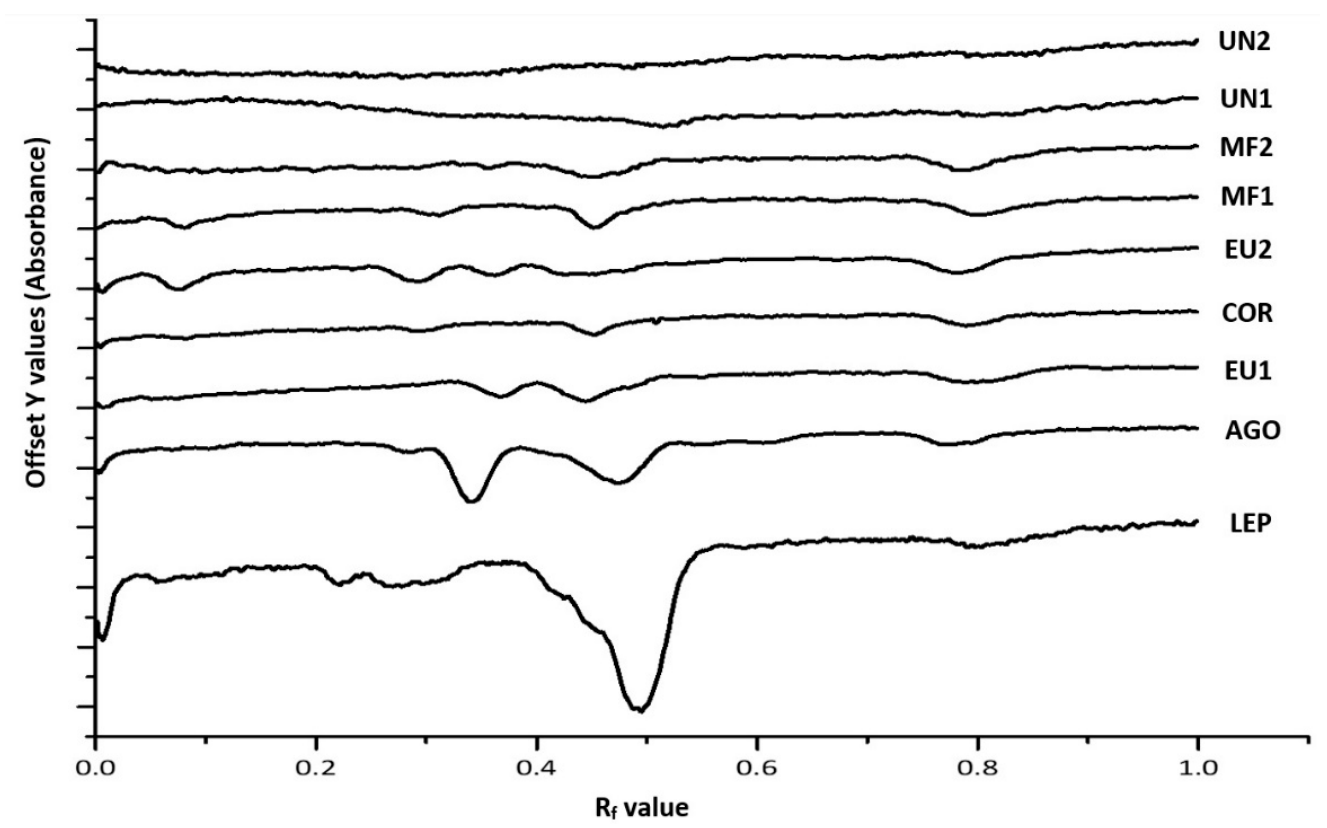

Figure 1. Organic honey extract chromatograms; $5 \mu \mathrm{L}$ of each honey extract.

The trends found for antioxidant activity of the investigated honeys were similar to other studies, where the total antioxidant activity using $\mathrm{DPPH}^{*}$ reagent was reported $[37,38]$. For example, the honey labelled as Manuka honey (LEP) displayed the highest level of activity in this study, and it was also reported as a highly antioxidant honey by others [39].

The value of this method is that it provides a more nuanced picture by capturing the antioxidant activity of individual honey constituents. For example, the honey labelled as Marri (COR) and the unspecified organic honey extract (MF1) displayed very similar total band antioxidant activity, but the HPTLC-DPPH analysis could demonstrate that only two bands (Rf 0.42 and 0.81 ) were mainly responsible for the antioxidant activity of the Marri honey extract (COR), whereas four different constituents (at Rf 0.09, 0.31, 0.48, and 0.81) contributed to the total band activity of the organic honey extract (MF1) (Table 2). Thus, the findings demonstrate that honeys differ in their antioxidant profiles, despite displaying similar total band activity in the HPTLC-DPPH assay.

It also appears that there might be common antioxidant constituents present across different honey organic extracts illustrated, for example, by common bands at Rf $0.806-0.809$ for COR and MF2, whereas the presence of other antioxidant constituents seems to be more tied to particular honeys. This can be seen, for instance, for the band at Rf 0.476 in LEP, which notably contributes to the extract's antioxidant activity, but does not seem to occur across most of the other honeys analysed in this study.

All monofloral honey extracts, except the one derived from Karri honey (EU1), displayed relatively high levels of antioxidant activity, which might be a reflection of their various phenolic and flavonoid constituents. However, it is interesting to note that not all honeys from unspecified floral sources were of the same antioxidant quality. Some of them displayed high levels (i.e., MF1 and MF2), whereas others (i.e., UN1 and UN2) had very little activity. A likely explanation is that the former two were produced by local beekeepers by mixing honeys of unspecified floral origins that might have carried some antioxidant activity. Honeys without a specified nectar source (UN1, UN2), on the other hand, only displayed negligible levels of antioxidant activity.

\subsection{Comparison of Honey Extracts' Floral Fingerprints with Antioxidant Fingerprints}

It is also interesting to compare the honey extracts' floral fingerprints, which are characteristic for their respective nectar sources (Figure 2), with the obtained antioxidant fingerprints (Figure 1). The HPTLC method, for the authentication of a honey's floral 
source based on floral fingerprints, was published earlier [33,35]. A direct comparison between the respective fingerprints demonstrates that constituents signifying a honey's floral source for authentication purposes might not necessarily contribute to its antioxidant activity. Table 3 directly compares the most important bands for authentication of the floral source with those considered key to the honey extract's antioxidant activity.

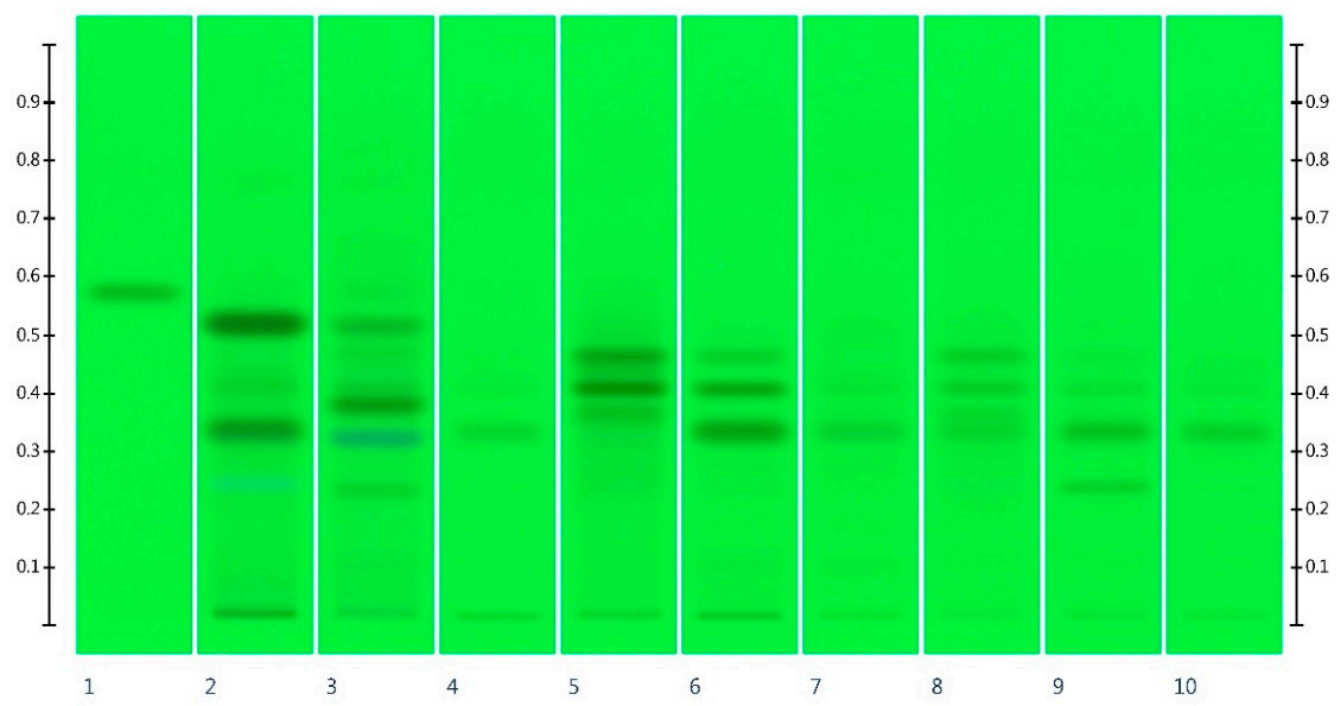

(a)
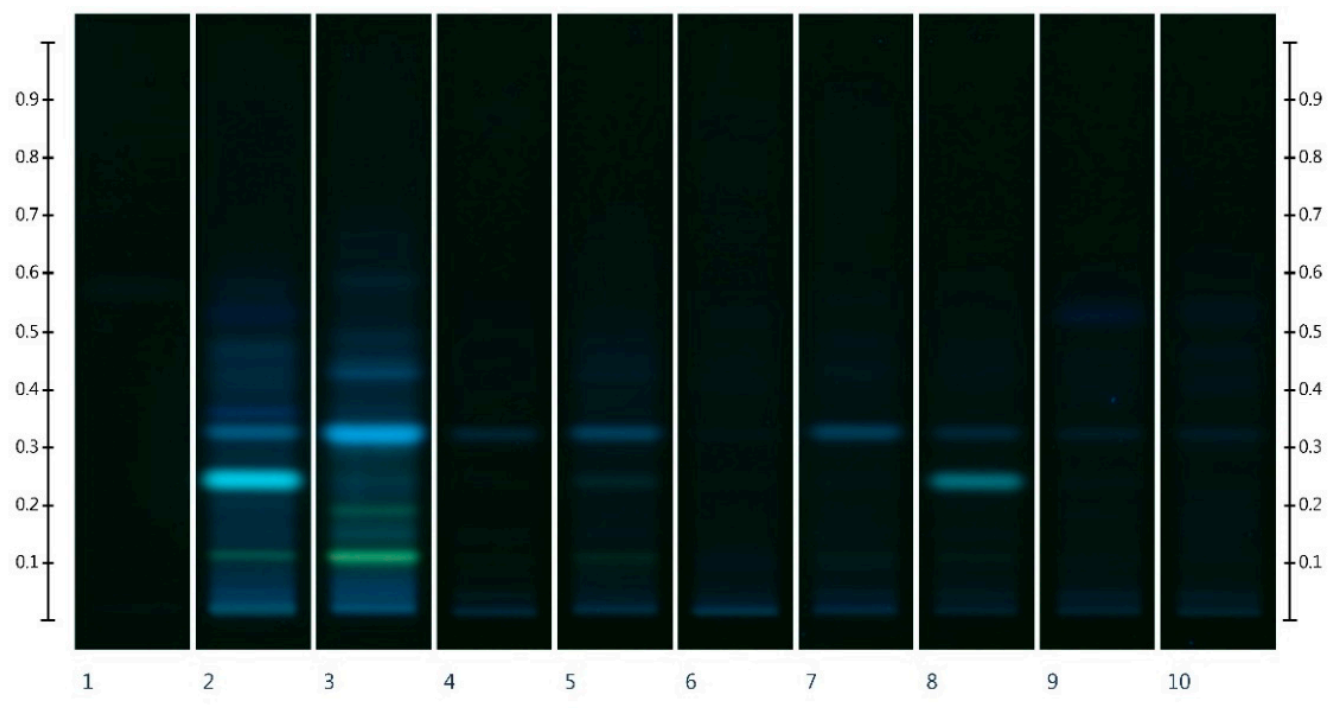

(b)

Figure 2. Cont. 


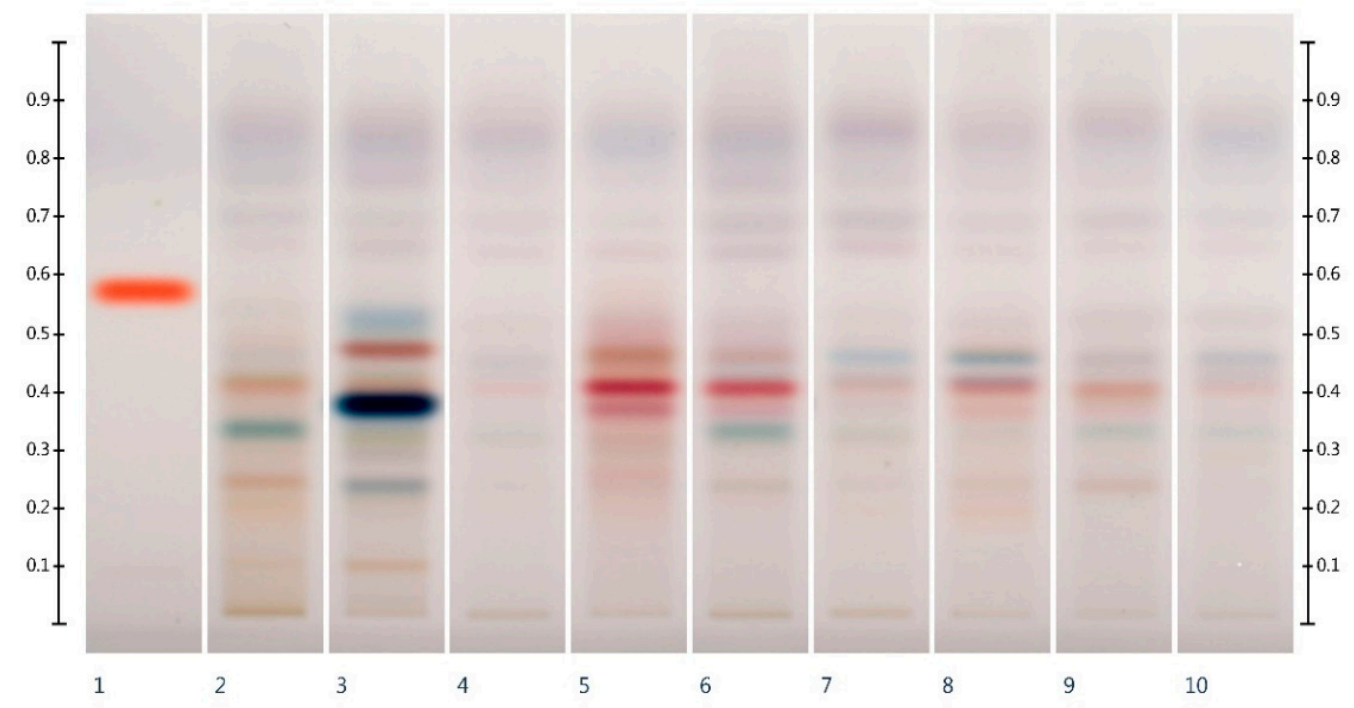

(c)

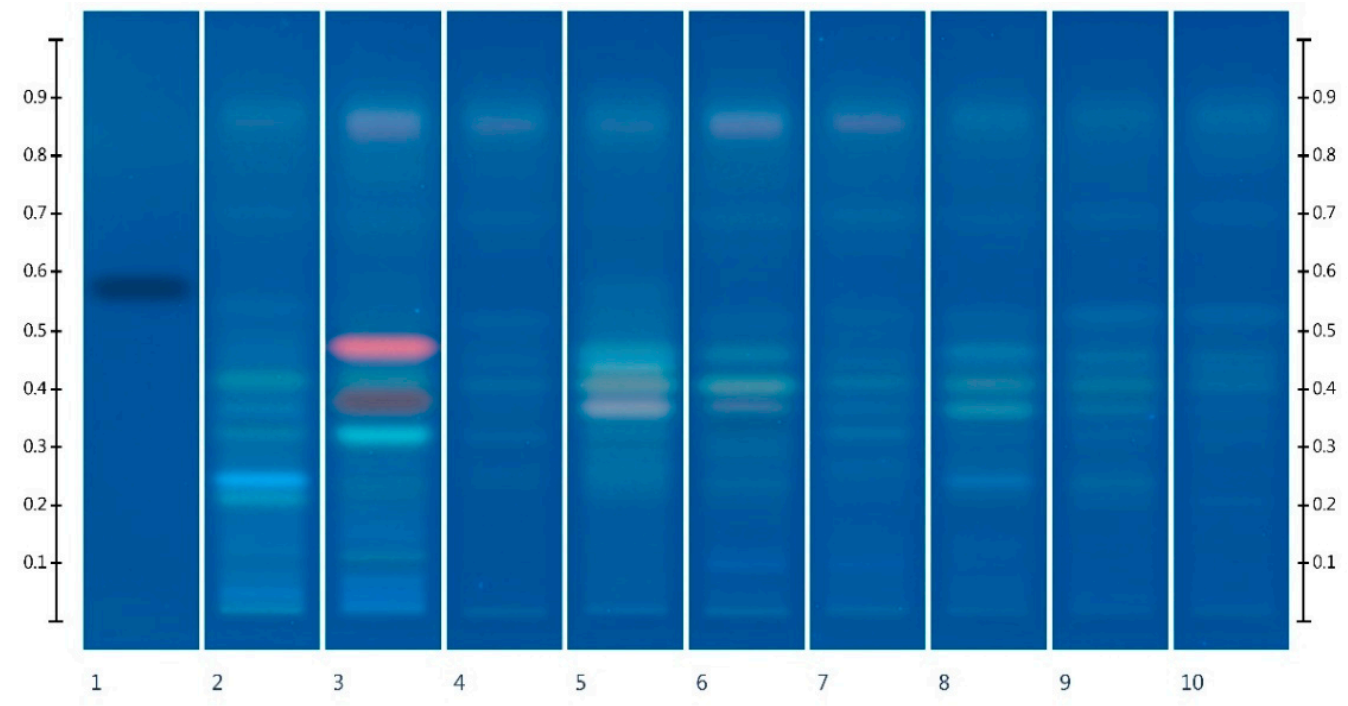

(d)

Figure 2. Honey extracts' floral fingerprints. (a) Images taken at R 254 after development, (b) R 366 after development, (c) white light after derivatisation with vanillin reagent, and (d) R 366 after derivatisation with vanillin reagent; Track 1-4,5,7-trihydroxyflavanon, Track 2-LEP, Track 3-AGO, Track 4-EU1, Track 5-COR, and Track 6-EU2, Track 7-MF1, Track 8-MF2, Track 9-UN1, and Track $10-\mathrm{UN} 2 ; 5 \mu \mathrm{L}$ of each honey extract.

Table 3. Comparison between antioxidant bands and floral fingerprint bands of organic extracts of commercial Western Australian honeys.

\begin{tabular}{|c|c|c|c|c|c|c|c|c|c|}
\hline \multirow{4}{*}{ ID } & \multirow{4}{*}{$\begin{array}{l}\text { Antioxidant } \\
\text { Bands (Rf) }\end{array}$} & \multicolumn{8}{|c|}{ Floral Fingerprint Bands (Rf) } \\
\hline & & \multicolumn{4}{|c|}{ After Development } & \multicolumn{4}{|c|}{ After Derivatisation } \\
\hline & & \multicolumn{2}{|c|}{ R 254} & \multicolumn{2}{|c|}{ R 366} & \multicolumn{2}{|c|}{ T White } & \multicolumn{2}{|c|}{ R 366} \\
\hline & & Rf & Colour & Rf & Colour & Rf & Colour & Rf & Colour \\
\hline \multirow{4}{*}{ LEP } & 0.27 & 0.24 & BRB & 0.12 & LY & 0.25 & & 0.20 & $\mathrm{BRB}$ \\
\hline & 0.47 & 0.35 & & 0.25 & $\mathrm{BRB}$ & 0.34 & $\mathrm{G}$ & 0.25 & $\mathrm{BRB}$ \\
\hline & 0.83 & 0.52 & & 0.33 & LB & 0.41 & $\mathrm{O}$ & 0.33 & \\
\hline & & & & & & 0.47 & $\mathrm{Y}$ & 0.42 & \\
\hline
\end{tabular}


Table 3. Cont.

\begin{tabular}{|c|c|c|c|c|c|c|c|c|c|}
\hline \multirow{4}{*}{ ID } & \multirow{4}{*}{$\begin{array}{l}\text { Antioxidant } \\
\text { Bands (Rf) }\end{array}$} & \multicolumn{8}{|c|}{ Floral Fingerprint Bands (Rf) } \\
\hline & & \multicolumn{4}{|c|}{ After Development } & \multicolumn{4}{|c|}{ After Derivatisation } \\
\hline & & \multicolumn{2}{|c|}{ R 254} & \multicolumn{2}{|c|}{ R 366} & \multicolumn{2}{|c|}{ T White } & \multicolumn{2}{|c|}{ R 366} \\
\hline & & $\mathbf{R f}$ & Colour & Rf & Colour & $\mathbf{R f}$ & Colour & $\mathbf{R f}$ & Colour \\
\hline \multirow{5}{*}{ AGO } & 0.35 & 0.23 & \multirow{5}{*}{$\mathrm{BRB}$} & 0.11 & $\mathrm{Y}$ & 0.10 & & 0.11 & \\
\hline & 0.49 & 0.33 & & 0.19 & LY & 0.25 & & 0.23 & \\
\hline & 0.78 & 0.39 & & 0.32 & BRB & 0.39 & DB & 0.32 & $\mathrm{G}$ \\
\hline & & 0.52 & & 0.42 & LB & 0.47 & BW & 0.38 & BW \\
\hline & & & & & & & & 0.48 & $\mathrm{R}$ \\
\hline \multirow{3}{*}{ EU1 } & 0.30 & 0.33 & & 0.33 & LB & 0.32 & & 0.32 & \\
\hline & 0.46 & & & & & 0.41 & & 0.40 & \\
\hline & 0.80 & & & & & 0.46 & & 0.52 & \\
\hline \multirow{4}{*}{ COR } & 0.43 & 0.37 & & 0.25 & & 0.37 & $\mathrm{P}$ & 0.25 & \\
\hline & 0.81 & 0.41 & & 0.32 & LB & 0.41 & $\mathrm{R}$ & 0.37 & LBW \\
\hline & & 0.47 & & & & 0.47 & $\mathrm{O}$ & 0.41 & DBW \\
\hline & & & & & & & & 0.45 & DB \\
\hline \multirow{4}{*}{ EU2 } & 0.08 & 0.34 & & & & 0.24 & & 0.10 & B \\
\hline & 0.41 & 0.41 & & & & 0.33 & G & 0.36 & DBW \\
\hline & 0.80 & 0.46 & & & & 0.40 & $\mathrm{R}$ & 0.40 & DBW \\
\hline & & & & & & 0.47 & BW & 0.46 & DBW \\
\hline \multirow{4}{*}{ MF1 } & 0.09 & 0.34 & & 0.33 & LB & & & 0.33 & \\
\hline & 0.31 & & & & & 0.42 & & 0.36 & \\
\hline & 0.48 & & & & & 0.46 & & 0.41 & \\
\hline & 0.81 & & & & & & & & \\
\hline \multirow{5}{*}{ MF2 } & 0.46 & 0.33 & & 0.11 & & 0.20 & & 0.23 & B \\
\hline & 0.81 & 0.41 & & 0.24 & BRB & 0.36 & $\mathrm{O}$ & 0.37 & BW \\
\hline & & 0.46 & & 0.32 & LB & 0.41 & LB & 0.41 & DBW \\
\hline & & & & & & 0.46 & B & 0.47 & DR \\
\hline & & & & & & & & 0.52 & \\
\hline \multirow{4}{*}{ UN1 } & 0.08 & 0.24 & & & & 0.25 & BW & 0.37 & \\
\hline & 0.51 & 0.34 & & 0.23 & & 0.33 & $\mathrm{G}$ & 0.41 & BW \\
\hline & 0.81 & 0.40 & & 0.32 & & 0.40 & BW & 0.46 & BW \\
\hline & & & & & & & & 0.54 & \\
\hline UN2 & Not Detected & 0.33 & & 0.31 & & $\mathrm{Ve}$ & int; not ea & listing & able \\
\hline
\end{tabular}

The Rf value of the standard (4,5,7-trihydroxyflavanon) was 0.58 (pink at T white light); Colour code: B-Blue, BW-Brown, R-Red, Y-Yellow, O-Orange, G-Green, P-Pink, LB-Light Blue, BRB-Bright Blue, DBW-Dull Brown, DB-Dark Blue, LY-Light Yellow.

\subsection{Tracking of Thermal Stability of Selected Honeys}

In order to explore the usefulness of HPTLC coupled with DPPH* derivatisation to track individual antioxidant honey constituents throughout their processing and storage, four different honeys, LEP, AGO, MF2, and UN1 (thus, two monofloral and two multifloral honey samples), were subjected to thermal stability testing, and their floral (Figure 3) and antioxidant (Figure 4, exemplary LEP only) fingerprints monitored for any potential changes.

As can be seen from Figure 3, the investigated honeys appear to be relatively resistant to change in the chemical composition of their organic extracts on exposure to moderate temperatures $\left(40-60^{\circ} \mathrm{C}\right)$, as even a continuous exposure over $48 \mathrm{~h}$ had only minor effects on the honeys' HTLPC profiles. 


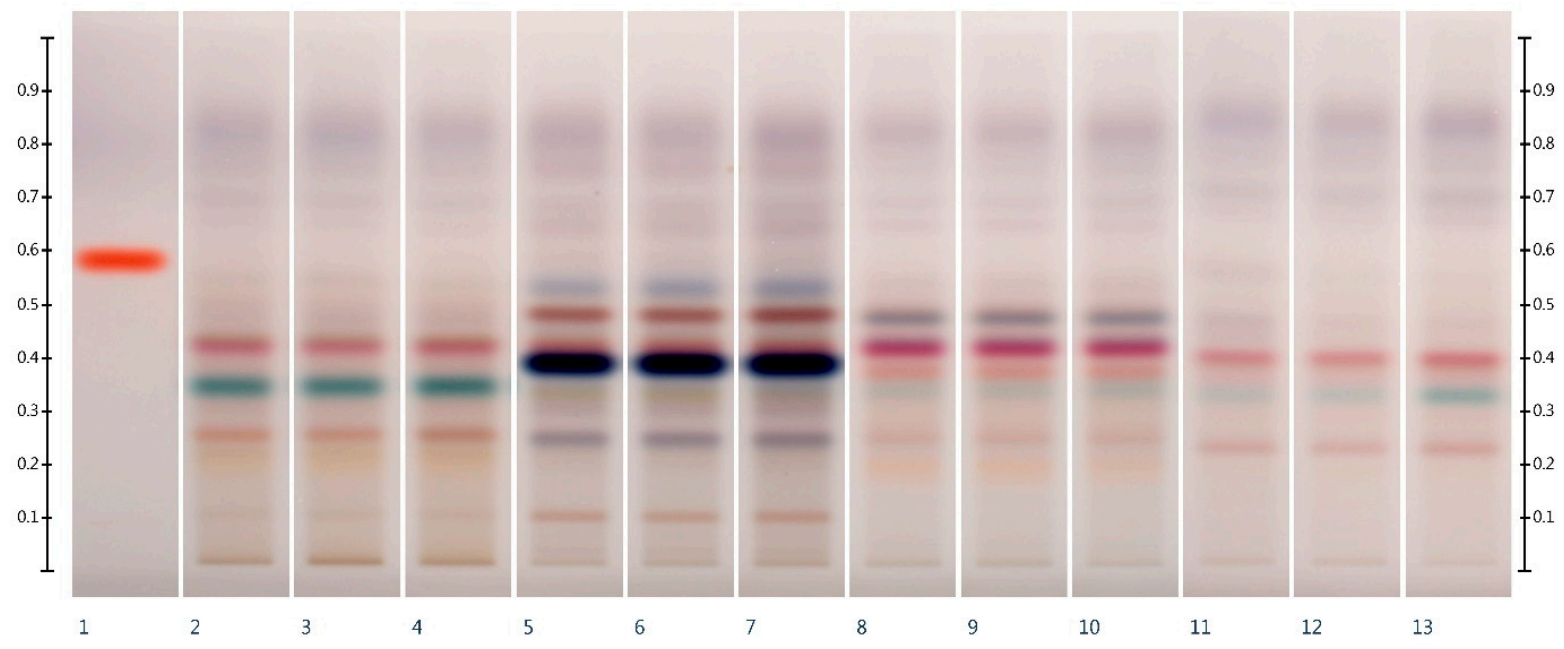

(a)

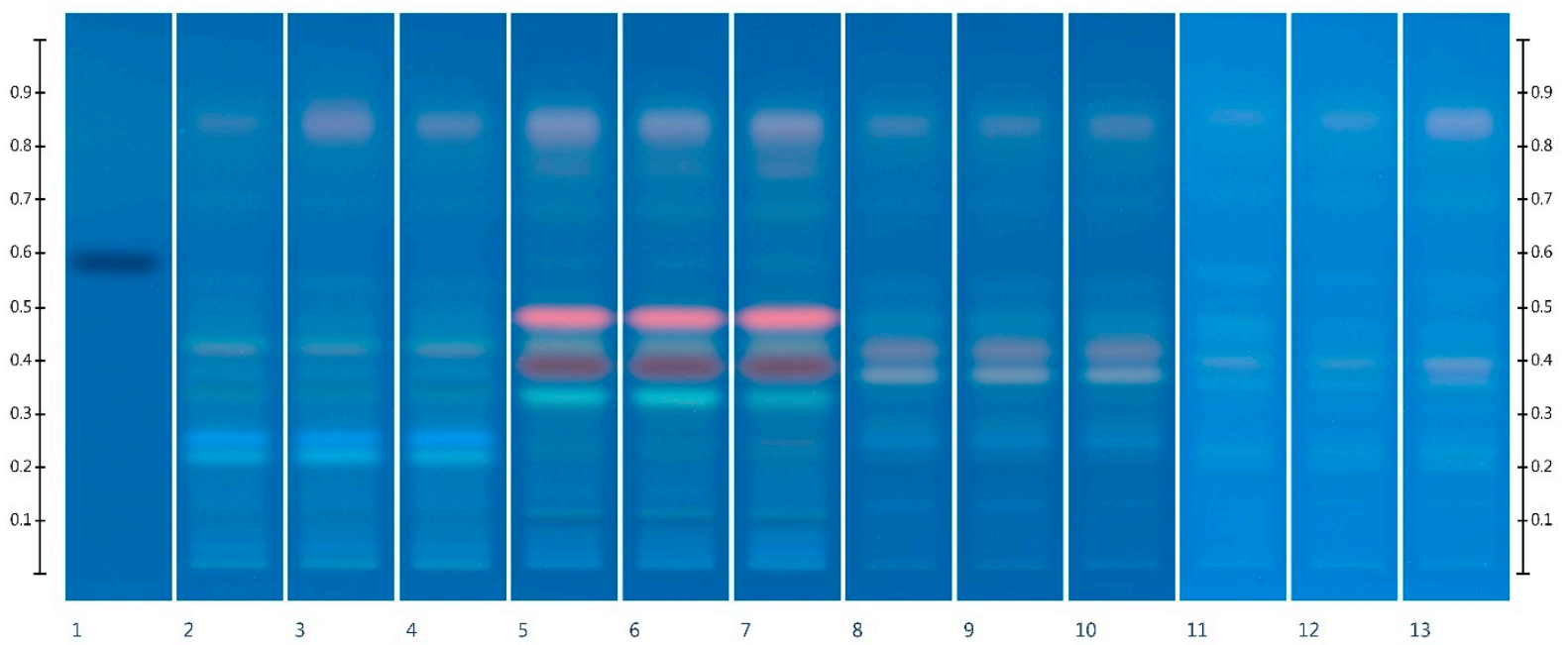

(b)

Figure 3. Floral fingerprints after thermal exposure: Images taken at (a) white light after derivatisation with vanillin reagent, and (b) R 366 after derivatisation with vanillin reagent; Track 1-4,5,7-trihydroxyflavanon, Track 2-LEP, Track 3-LEP at $40{ }^{\circ} \mathrm{C}$ after $48 \mathrm{~h}$, Track 4 - LEP at $60{ }^{\circ} \mathrm{C}$ after $48 \mathrm{~h}$, Track 5-AGO, Track 6-AGO at $40{ }^{\circ} \mathrm{C}$ after $48 \mathrm{~h}$, Track 7-AGO at $60{ }^{\circ} \mathrm{C}$ after $48 \mathrm{~h}$, Track 8 - MF2, Track $9-\mathrm{MF} 2$ at $40^{\circ} \mathrm{C}$ after $48 \mathrm{~h}$, Track $10-\mathrm{MF} 2$ at $60^{\circ} \mathrm{C}$ after $48 \mathrm{~h}$, Track $11-\mathrm{UN} 1$, Track 12-UN1 at $40{ }^{\circ} \mathrm{C}$ after $48 \mathrm{~h}$, and Track $13-\mathrm{UN} 1$ at $60{ }^{\circ} \mathrm{C}$ after $48 \mathrm{~h} ; 5 \mu \mathrm{L}$ of each honey extract.

HPTLC analysis coupled with DPPH* derivatisation allowed us to quantify the potential effect of heating on antioxidant band activity. As can be seen in Figure 4 exemplary for Manuka honey, some of the band intensities changed over $48 \mathrm{~h}$ of thermal exposure, which ultimately also impacted the honey's total band activity.

Thermal exposure experiments were conducted in triplicate for each investigated honey (LEP, AGO, MF2, and UN1). For better comparison, antioxidant band activities at each sampling time point were expressed as percentage (\%) antioxidant band activity of the value found at the start of the experiment. 


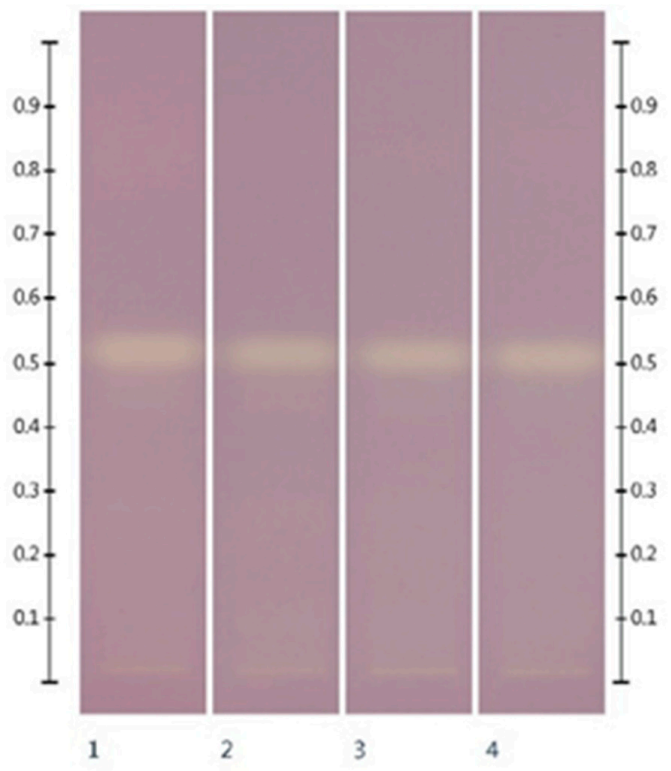

(a)

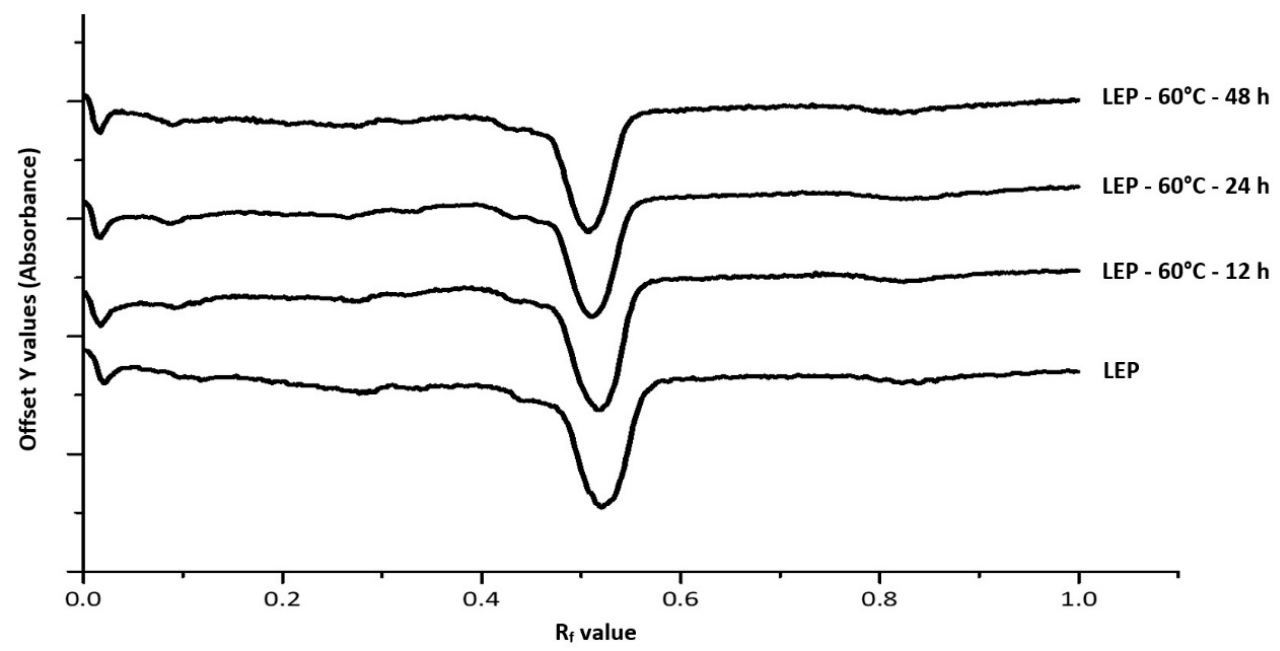

(b)

Figure 4. Antioxidant band activity after thermal exposure. Images taken at (a) white light after derivatisation with DPPH reagent and (b) their respective chromatograms; Track $1-\mathrm{LEP}$, Track $2-\mathrm{LEP}$ at $60^{\circ} \mathrm{C}$ after $12 \mathrm{~h}$, Track $3-\mathrm{LEP}$ at $60^{\circ} \mathrm{C}$ after $24 \mathrm{~h}$, Track 4 - LEP at $60{ }^{\circ} \mathrm{C}$ after $48 \mathrm{~h} ; 5 \mu \mathrm{L}$ of each honey extract.

Based on one-way ANOVA, statistically significant differences $(p<0.05)$ between various honeys exposed to different temperatures were found at different time points. Pairwise ANOVA (TukeyHSD) revealed that MF2 and UN1 were stable in their \% antioxidant band activity following exposure for up to $48 \mathrm{~h}$ at $40^{\circ} \mathrm{C}$ and $60^{\circ} \mathrm{C}$ ( $p$ values ranging between 0.994 and 1.000) (Figure 5c,d). In the case of $\mathrm{AGO}$, no significant differences could be found at $40{ }^{\circ} \mathrm{C}$ (Figure $5 \mathrm{~b}$ ), whereas for LEP stored at $40{ }^{\circ} \mathrm{C}$ (Figure 5a), there were no changes in antioxidant band activity up to $24 \mathrm{~h}$ of heat exposure $(p=0.983)$, but at $48 \mathrm{~h}$ the honey's antioxidant band activity was found to have significantly decreased to $83.16 \pm 1.38 \%$ of the baseline value $(p=0.00004)$. Interestingly, $\%$ antioxidant band activity of AGO significantly decreased to $88.45 \pm 2.83 \%$ of baseline $(p=0.0304)$ when stored at $60{ }^{\circ} \mathrm{C}$ for $12 \mathrm{~h}$, but beyond $12 \mathrm{~h}$, the \% antioxidant band activity increased again $(89.67 \pm 7.33 \%$ at $24 \mathrm{~h}, p=0.0996$ and $96.88 \pm 6.89 \%$ at $48 \mathrm{~h}, p=0.999$ ) (Figure 5b). A similar trend could be seen for LEP kept at $60{ }^{\circ} \mathrm{C}$, where statistically significant differences were found beyond $12 \mathrm{~h}$ storage (decrease to $85.08 \pm 8.91 \%$ at $24 \mathrm{~h}, p=0.00056$ and increase to $88.38 \pm 6.20 \%$ 
at $48 \mathrm{~h}, p=0.0282$ ) (Figure 5a), which might be explained by the potential formation or release of antioxidant compounds over prolonged exposure to higher temperatures. The literature suggests, for example, that pollen, which is naturally present in honey, can degrade at higher temperature and release antioxidant compounds [18,40], which would then contribute to the overall antioxidant band activity. A more in-depth analysis of this phenomenon was, however, outside the scope of this study.

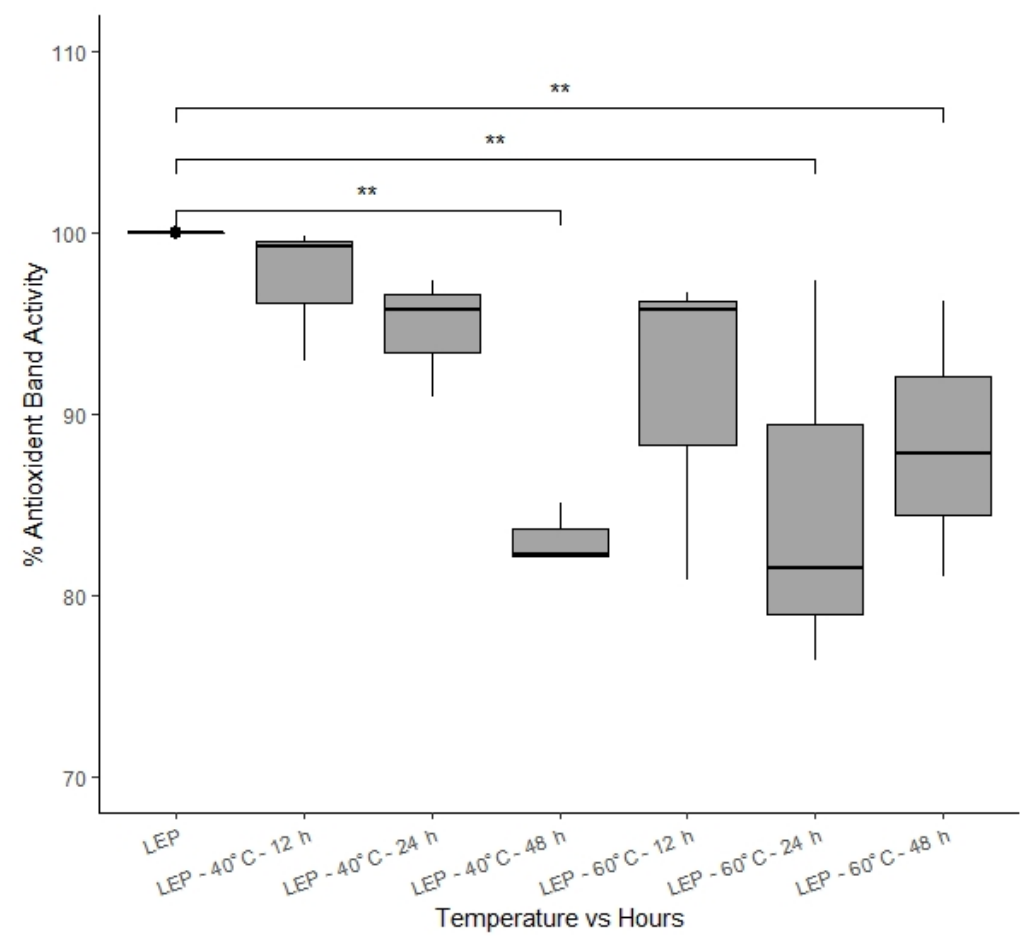

(a)

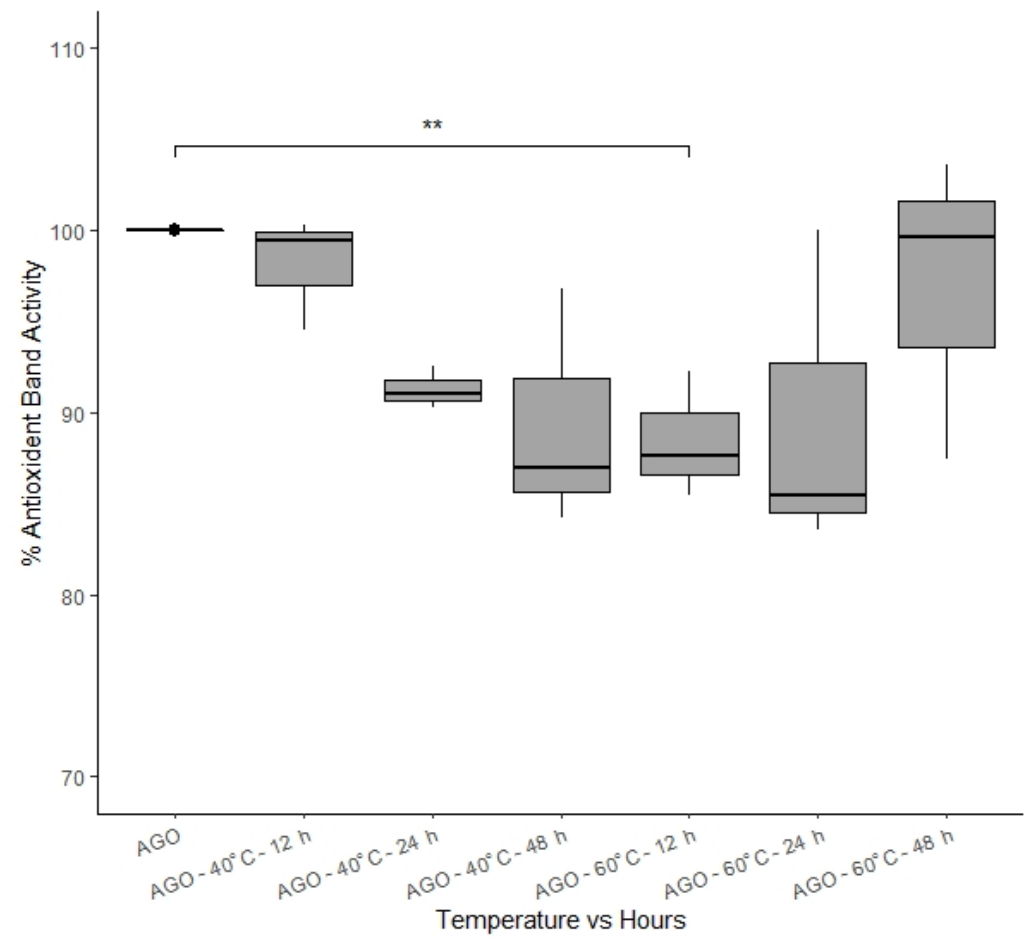

(b)

Figure 5. Cont. 


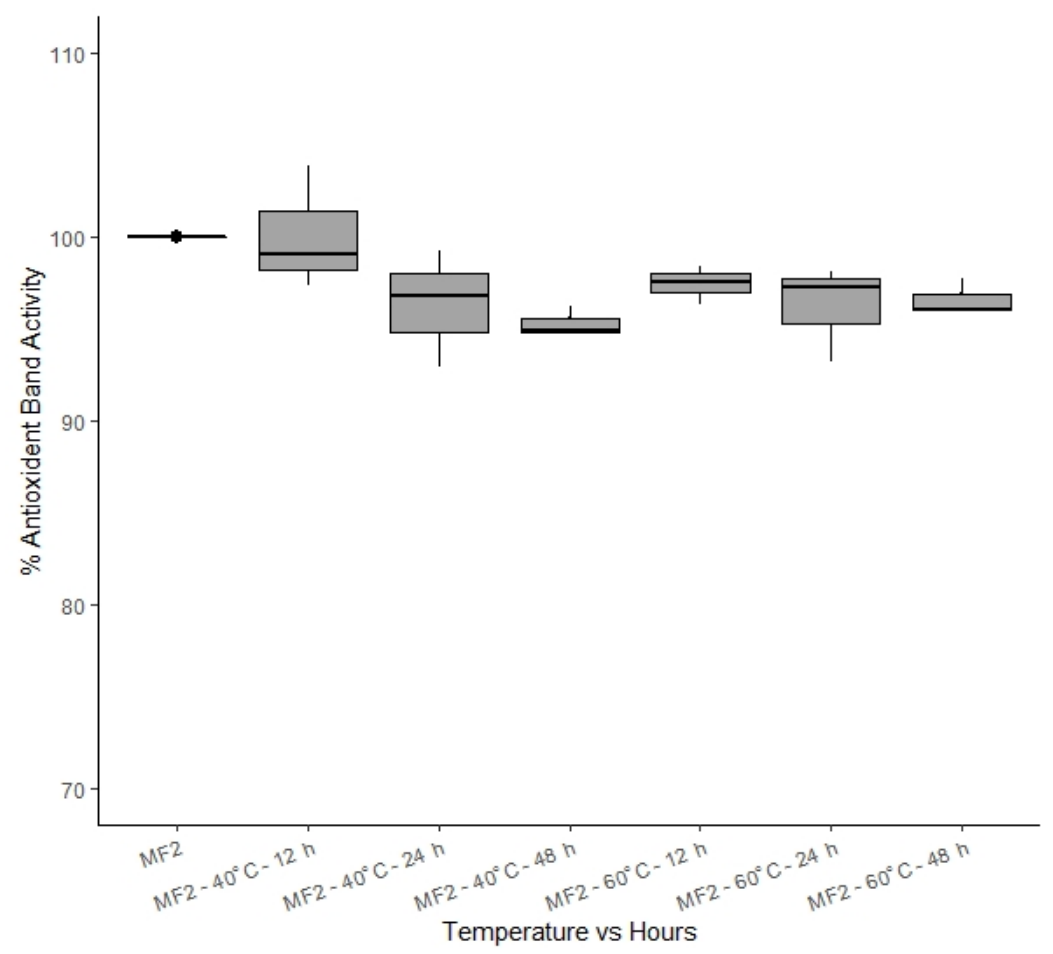

(c)

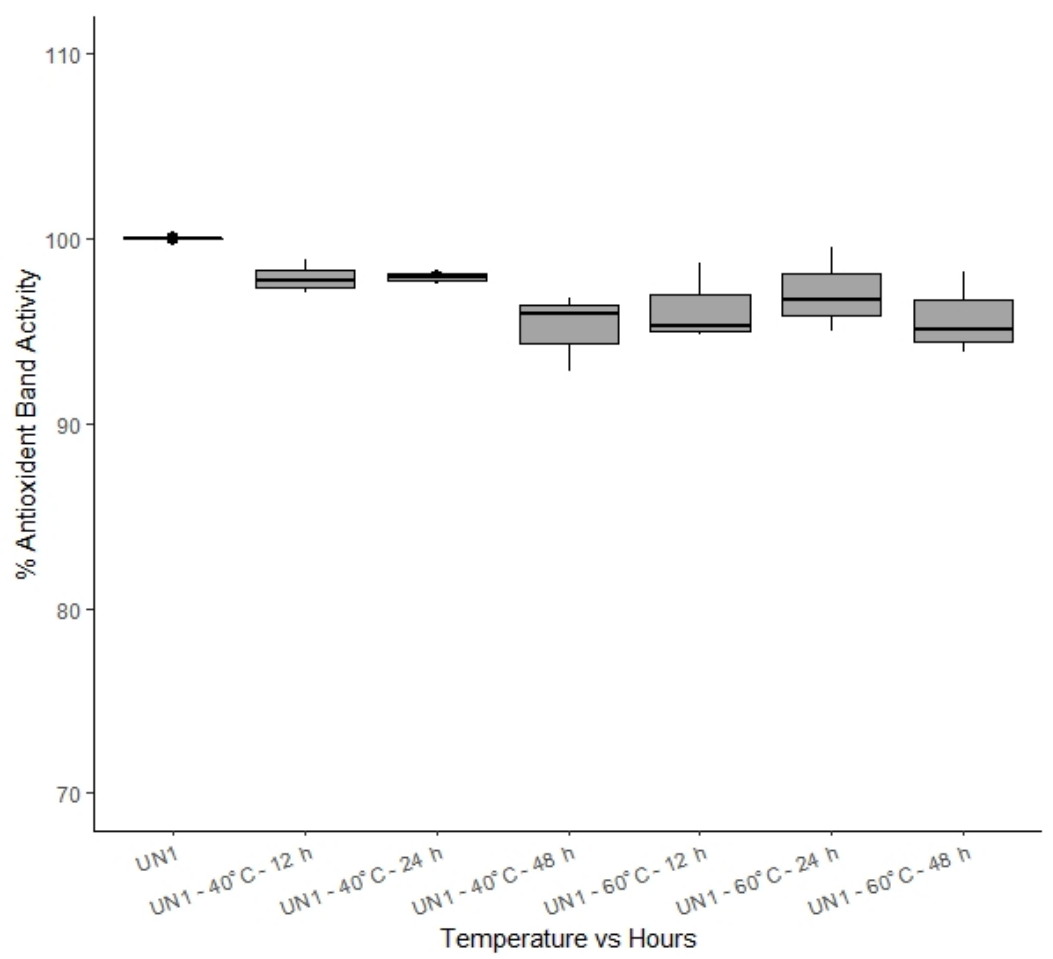

(d)

Figure 5. (a-d) Graphical representation of \% antioxidant band activity of different honey extracts at different temperature time-points. Significance ${ }^{* *}$ is indicated for $p<0.05$.

Overall, it appears that honeys with higher antioxidant band activities tend to be more affected by temperature, leading in most instances to a decrease of activity from baseline values, a finding which is also supported by other studies [29,40-43]. Additionally, as expected, a higher temperature seems to exert a stronger effect, as at $40{ }^{\circ} \mathrm{C}$, most honeys were found to be stable, except LEP when exposed for $48 \mathrm{~h}$. At the higher storage 
temperature of $60^{\circ} \mathrm{C}$, honeys with higher antioxidant band activities were affected even at shorter exposure times (beyond $12 \mathrm{~h}$ ). More honeys would need to be examined to confirm the generalisability of these trends; however, this is outside the scope of this study, which does not aim to investigate particular honeys' antioxidant characteristics, but to demonstrate the usefulness of HPTLC-DPPH fingerprinting for the tracking of antioxidant activity of honeys.

\section{Conclusions}

High-Performance Thin Layer Chromatography (HPTLC) coupled with DPPH* derivatisation allows for a better understanding of the individual constituents responsible for a honey extract's antioxidant activity. There are noticeable differences between honeys of different floral sources even if their total antioxidant band activity appears to be similar. Thus, the method offers both qualitative (antioxidant fingerprint) and quantitative (antioxidant band activity expressed as gallic acid equivalents) dimensions that help to differentiate between honeys of different botanical origin, and thus complement the honey extracts' floral fingerprints. Next to more ubiquitous antioxidant constituents, unique phytochemicals also appear to be present in some of these honeys that contribute to their antioxidant properties. While their chemical identity has not yet been established, with the combination of HPTLC analysis and DPPH* derivatisation, their relative contribution to the extract's antioxidant effect can nonetheless be quantified as gallic acid equivalents, and their potential change on exposure to processing stressors like heat can be documented.

Given the increasing popularity of HPTLC analysis in natural product and food chemistry, it can be assumed that the combination of HPTLC with DPPH* derivatisation might also be a useful quality control tool for other natural products and food items where the maintenance of antioxidant activity throughout production and handling is also paramount.

Author Contributions: Conceptualization, M.K.I. and C.L.; methodology, M.K.I., T.S. and C.L.; formal analysis, M.K.I. and T.S.; writing-original draft preparation, M.K.I.; writing-review and editing, C.L., T.S. and L.Y.L.; supervision, C.L., L.Y.L. and K.H.; project administration, C.L.; funding acquisition, C.L. All authors have read and agreed to the published version of the manuscript.

Funding: This research was funded by the Cooperative Research Centre for Honey Bee Products (CRC HBP).

Institutional Review Board Statement: Not applicable.

Informed Consent Statement: Not applicable.

Data Availability Statement: Not applicable.

Acknowledgments: We thank Chromatech Scientific for their technical support of this project.

Conflicts of Interest: The authors declare no conflict of interest. The funders had no role in the design of the study; in the collection, analyses, or interpretation of data; in the writing of the manuscript, or in the decision to publish the results.

\section{References}

1. Al-Farsi, M.; Al-Amri, A.; Al-Hadhrami, A.; Al-Belushi, S. Color, flavonoids, phenolics and antioxidants of Omani honey. Heliyon 2018, 4, e00874. [CrossRef]

2. Bueno-Costa, F.M.; Zambiazi, R.C.; Bohmer, B.W.; Chaves, F.C.; Silva, W.P.d.; Zanusso, J.T.; Dutra, I. Antibacterial and antioxidant activity of honeys from the state of Rio Grande do Sul, Brazil. LWT-Food Sci. Technol. 2016, 65, 333-340. [CrossRef]

3. Alimentarius, C. Revised codex standard for honey. Codex Stand. 2001, 12, 1982.

4. Soares, S.; Pinto, D.; Rodrigues, F.; Alves, R.C.; Oliveira, M. Portuguese Honeys from Different Geographical and Botanical Origins: A 4-Year Stability Study Regarding Quality Parameters and Antioxidant Activity. Molecules 2017, 22, 1338. [CrossRef] [PubMed]

5. Kuropatnicki, A.K.; Kłósek, M.; Kucharzewski, M. Honey as medicine: Historical perspectives. J. Apic. Res. 2018, 57, 113-118. [CrossRef]

6. Forrest, R.D. Early history of wound treatment. J. R. Soc. Med. 1982, 75, 198-205. [PubMed] 
7. Estevinho, L.; Pereira, A.P.; Moreira, L.; Dias, L.G.; Pereira, E. Antioxidant and antimicrobial effects of phenolic compounds extracts of Northeast Portugal honey. Food Chem. Toxicol. 2008, 46, 3774-3779. [CrossRef] [PubMed]

8. Gheldof, N.; Engeseth, N.J. Antioxidant Capacity of Honeys from Various Floral Sources Based on the Determination of Oxygen Radical Absorbance Capacity and Inhibition of in Vitro Lipoprotein Oxidation in Human Serum Samples. J. Agric. Food Chem. 2002, 50, 3050-3055. [CrossRef] [PubMed]

9. Masalha, M.; Abu-Lafi, S.; Abu-Farich, B.; Rayan, M.; Issa, N.; Zeidan, M.; Rayan, A. A New Approach for Indexing Honey for Its Heath/Medicinal Benefits: Visualization of the Concept by Indexing Based on Antioxidant and Antibacterial Activities. Medicines 2018, 5, 135. [CrossRef] [PubMed]

10. El-Haskoury, R.; Al-Waili, N.; Kamoun, Z.; Makni, M.; Al-Waili, H.; Lyoussi, B. Antioxidant Activity and Protective Effect of Carob Honey in CCl4-induced Kidney and Liver Injury. Arch. Med. Res. 2018, 49, 306-313. [CrossRef]

11. Dzugan, M.; Tomczyk, M.; Sowa, P.; Grabek-Lejko, D. Antioxidant Activity as Biomarker of Honey Variety. Molecules 2018, 23, 2069. [CrossRef] [PubMed]

12. Ozkok, D.; Silici, S. Antioxidant activities of honeybee products and their mixtures. Food Sci. Biotechnol. 2017, 26, 201-206. [CrossRef]

13. Neupane, B.P.; Chaudhary, D.; Paudel, S.; Timsina, S.; Chapagain, B.; Jamarkattel, N.; Tiwari, B.R. Himalayan honey loaded iron oxide nanoparticles: Synthesis, characterization and study of antioxidant and antimicrobial activities. Int. J. Nanomed. 2019, 14, 3533-3541. [CrossRef] [PubMed]

14. Di Marco, G.; Gismondi, A.; Panzanella, L.; Canuti, L.; Impei, S.; Leonardi, D.; Canini, A. Botanical influence on phenolic profile and antioxidant level of Italian honeys. J. Food Sci. Technol. 2018, 55, 4042-4050. [CrossRef] [PubMed]

15. Ronsisvalle, S.; Lissandrello, E.; Fuochi, V.; Petronio Petronio, G.; Straquadanio, C.; Crasci, L.; Panico, A.; Milito, M.; Cova, A.M.; Tempera, G.; et al. Antioxidant and antimicrobial properties of Casteanea sativa Miller chestnut honey produced on Mount Etna (Sicily). Nat. Prod. Res. 2019, 33, 843-850. [CrossRef]

16. Cheung, Y.; Meenu, M.; Yu, X.; Xu, B. Phenolic acids and flavonoids profiles of commercial honey from different floral sources and geographic sources. Int. J. Food Prop. 2019, 22, 290-308. [CrossRef]

17. Otmani, I.; Abdennour, C.; Dridi, A.; Kahalerras, L.; Halima-Salem, A. Characteristics of the bitter and sweet honey from Algeria Mediterranean coast. Vet. World 2019, 12, 551-557. [CrossRef] [PubMed]

18. Molaveisi, M.; Beigbabaei, A.; Akbari, E.; Noghabi, M.S.; Mohamadi, M. Kinetics of temperature effect on antioxidant activity, phenolic compounds and color of Iranian jujube honey. Heliyon 2019, 5, e01129. [CrossRef]

19. Gul, A.; Pehlivan, T. Antioxidant activities of some monofloral honey types produced across Turkey. Saudi J. Biol. Sci. 2018, 25, 1056-1065. [CrossRef]

20. Bendini, A.; Cerretani, L.; Pizzolante, L.; Toschi, T.G.; Guzzo, F.; Ceoldo, S.; Marconi, A.M.; Andreetta, F.; Levi, M. Phenol content related to antioxidant and antimicrobial activities of Passiflora spp. extracts. Eur. Food Res. Technol. 2006, 223, 102-109. [CrossRef]

21. Akar, Z.; Küçük, M.; Doğan, H. A new colorimetric DPPH(•) scavenging activity method with no need for a spectrophotometer applied on synthetic and natural antioxidants and medicinal herbs. J. Enzyme Inhib. Med. Chem. 2017, 32, 640-647. [CrossRef] [PubMed]

22. Prakash, A.; Rigelhof, F.; Miller, E. Medallion Laboratories Analytical Progress: Antioxidant Activity; DeVries, J., Ed.; Medallion Laboratories: Minneapolis, MN, USA, 2001; Volume 19, pp. 1-6.

23. Schaich, K.M.; Tian, X.; Xie, J. Reprint of "Hurdles and pitfalls in measuring antioxidant efficacy: A critical evaluation of ABTS, DPPH, and ORAC assays". J. Funct. Foods 2015, 18, 782-796. [CrossRef]

24. Hostalkova, A.; Klingelhofer, I.; Morlock, G.E. Comparison of an HPTLC method with the Reflectoquant assay for rapid determination of 5-hydroxymethylfurfural in honey. Anal. Bioanal. Chem. 2013, 405, 9207-9218. [CrossRef]

25. Stanek, N.; Jasicka-Misiak, I. HPTLC Phenolic Profiles as Useful Tools for the Authentication of Honey. (Report). Food Anal. Methods 2018, 11, 2979. [CrossRef]

26. Kato, Y.; Umeda, N.; Maeda, A.; Matsumoto, D.; Kitamoto, N.; Kikuzaki, H. Identification of a novel glycoside, leptosin, as a chemical marker of manuka honey. J. Agric. Food Chem. 2012, 60, 3418-3423. [CrossRef]

27. Islam, M.K.; Sostaric, T.; Lim, L.Y.; Hammer, K.; Locher, C. Development and validation of an HPTLC-DPPH assay and its application to the analysis of honey. JPC J. Planar Chromat. 2020, 33, 301-311. [CrossRef]

28. Escriche, I.; Visquert, M.; Juan-Borrás, M.; Fito, P. Influence of simulated industrial thermal treatments on the volatile fractions of different varieties of honey. Food Chem. 2009, 112, 329-338. [CrossRef]

29. Escriche, I.; Kadar, M.; Juan-Borrás, M.; Domenech, E. Suitability of antioxidant capacity, flavonoids and phenolic acids for floral authentication of honey. Impact of industrial thermal treatment. Food Chem. 2014, 142, 135-143. [CrossRef]

30. Bucekova, M.; Juricova, V.; Di Marco, G.; Gismondi, A.; Leonardi, D.; Canini, A.; Majtan, J. Effect of thermal liquefying of crystallised honeys on their antibacterial activities. Food Chem. 2018, 269, 335-341. [CrossRef] [PubMed]

31. Kowalski, S. Changes of antioxidant activity and formation of 5-hydroxymethylfurfural in honey during thermal and microwave processing. Food Chem. 2013, 141, 1378-1382. [CrossRef] [PubMed]

32. Yang, W.; Zhang, C.; Li, C.; Huang, Z.Y.; Miao, X. Pathway of 5-hydroxymethyl-2-furaldehyde formation in honey. J. Food Sci. Technol. 2019, 56, 2417-2425. [CrossRef]

33. Locher, C.; Neumann, J.; Sostaric, T. Authentication of honeys of different floral origins via high-performance thin-layer chromatographic fingerprinting. JPC J. Planar Chromat. 2017, 30, 57-62. [CrossRef] 
34. Ibrahim, R.S.; Khairy, A.; Zaatout, H.H.; Hammoda, H.M.; Metwally, A.M. Digitally-optimized HPTLC coupled with image analysis for pursuing polyphenolic and antioxidant profile during alfalfa sprouting. J. Chromatogr. B Analyt. Technol. Biomed. Life Sci. 2018, 1099, 92-96. [CrossRef] [PubMed]

35. Locher, C.; Tang, E.; Neumann, J.; Sostaric, T. High-performance thin-layer chromatography profiling of Jarrah and Manuka honeys. JPC J. Planar Chromat. 2018, 31, 181-189. [CrossRef]

36. Team, R.C. R: A Language and Environment for Statistical Computing; R Foundation for Statistical Computing: Vienna, Austria, 2020.

37. Almasaudi, S.B.; Abbas, A.T.; Al-Hindi, R.R.; El-Shitany, N.A.; Abdel-Dayem, U.A.; Ali, S.S.; Saleh, R.M.; Al Jaouni, S.K.; Kamal, M.A.; Harakeh, S.M. Manuka Honey Exerts Antioxidant and Anti-Inflammatory Activities That Promote Healing of Acetic Acid-Induced Gastric Ulcer in Rats. Evid. Based Complement. Alternat. Med. 2017, 2017, 5413917. [CrossRef] [PubMed]

38. Yao, L.; Datta, N.; Tomás-Barberán, F.A.; Ferreres, F.; Martos, I.; Singanusong, R. Flavonoids, phenolic acids and abscisic acid in Australian and New Zealand Leptospermum honeys. Food Chem. 2003, 81, 159-168. [CrossRef]

39. Alzahrani, H.A.; Alsabehi, R.; Boukraâ, L.; Abdellah, F.; Bellik, Y.; Bakhotmah, B.A. Antibacterial and antioxidant potency of floral honeys from different botanical and geographical origins. Molecules 2012, 17, 10540-10549. [CrossRef]

40. Karabagias, V.K.; Karabagias, I.K.; Gatzias, I. The impact of different heating temperatures on physicochemical, color attributes, and antioxidant activity parameters of Greek honeys. J. Food Process Eng. 2018, 41, e12668. [CrossRef]

41. Saxena, S.; Gautam, S.; Sharma, A. Physical, biochemical and antioxidant properties of some Indian honeys. Food Chem. 2010, 118, 391-397. [CrossRef]

42. Baltrušaitytè, V.; Venskutonis, P.R.; Čeksterytè, V. Radical scavenging activity of different floral origin honey and beebread phenolic extracts. Food Chem. 2007, 101, 502-514. [CrossRef]

43. Zarei, M.; Fazlara, A.; Tulabifard, N. Effect of thermal treatment on physicochemical and antioxidant properties of honey. Heliyon 2019, 5, e01894. [CrossRef] [PubMed] 